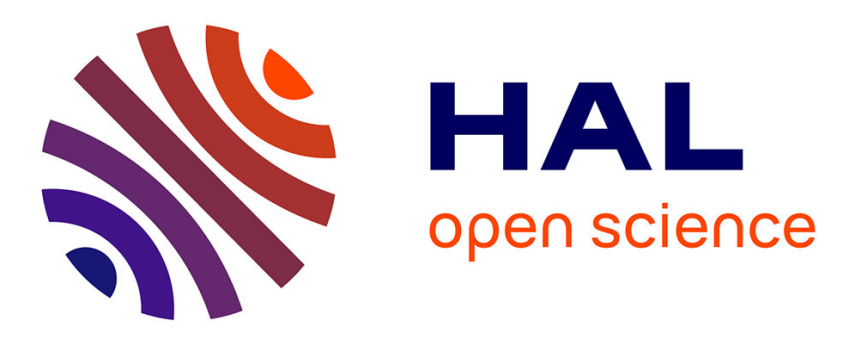

\title{
Standardization of activated sludge for biodegradation tests
}

\author{
Gabriela A. Vázquez-Rodríguez, Rosa Icela Beltrán-Hernández, Claudia \\ Coronel-Olivares, Jean-Luc Rols
}

\section{- To cite this version:}

Gabriela A. Vázquez-Rodríguez, Rosa Icela Beltrán-Hernández, Claudia Coronel-Olivares, Jean-Luc Rols. Standardization of activated sludge for biodegradation tests. Analytical and Bioanalytical Chemistry, 2011, vol. 401, pp. 1127-1137. 10.1007/s00216-011-5212-z . hal-00909018

\section{HAL Id: hal-00909018 https://hal.science/hal-00909018}

Submitted on 25 Nov 2013

HAL is a multi-disciplinary open access archive for the deposit and dissemination of scientific research documents, whether they are published or not. The documents may come from teaching and research institutions in France or abroad, or from public or private research centers.
L'archive ouverte pluridisciplinaire HAL, est destinée au dépôt et à la diffusion de documents scientifiques de niveau recherche, publiés ou non, émanant des établissements d'enseignement et de recherche français ou étrangers, des laboratoires publics ou privés. 


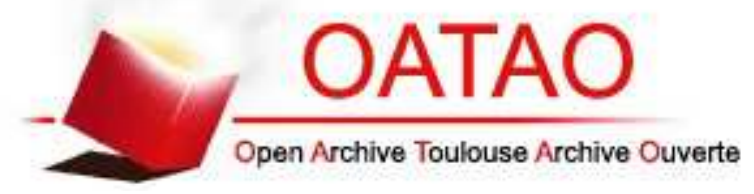

\section{Open Archive TOULOUSE Archive Ouverte (OATAO)}

OATAO is an open access repository that collects the work of Toulouse researchers and makes it freely available over the web where possible.

This is an author-deposited version published in : http://oatao.univ-toulouse.fr/ Eprints ID : 10243

To link to this article : doi:10.1007/s00216-011-5212-z

URL : http://dx.doi.org/10.1007/s00216-011-5212-z

To cite this version : Vázquez-Rodríguez, Gabriela A. and BeltránHernández, Rosa Icela and Coronel-Olivares, Claudia and Rols, JeanLuc Standardization of activated sludge for biodegradation tests. (2011) Analytical and Bioanalytical Chemistry, vol. 401 (n 4). pp. 11271137. ISSN 1618-2642

Any correspondance concerning this service should be sent to the repository administrator: staff-oatao@ listes-diff.inp-toulouse.fr 


\title{
Standardization of activated sludge for biodegradation tests
}

\author{
Gabriela A. Vázquez-Rodríguez • \\ Rosa Icela Beltrán-Hernández • \\ Claudia Coronel-Olivares • Jean-Luc Rols
}

\begin{abstract}
Activated sludges are an inoculum source commonly used in biodegradation studies, as wastewater treatment facilities constitute an entry point to the environment for many chemicals. In this paper, the main issues relating to the use of activated sludge in biodegradability tests are presented. Special attention is also devoted to discussing the factors affecting both the activity of the microbial communities and the test results. After a short survey of the state of the art of microbiology of activated sludge, the paper focuses on the methods used to reduce the variations in the diversity, quality and quantity of these communities. Finally, use of surrogates as reference materials in biodegradability tests is discussed.
\end{abstract}

Keywords Bioassays · Bioanalytical methods · Sludge · Reference materials

\author{
Abbreviations \\ BDOC Biodegradable dissolved organic carbon \\ BOD Biochemical oxygen demand \\ G. A. Vázquez-Rodríguez $(\bowtie) \cdot R$. I. Beltrán-Hernández • \\ C. Coronel-Olivares \\ Centro de Investigaciones Químicas, \\ Universidad Autónoma del Estado de Hidalgo, \\ Cd. Universitaria, Carretera Pachuca-Tulancingo km. 4.5, \\ Pachuca Hgo 42184, Mexico \\ e-mail: gvazquez@uaeh.edu.mx
}

\section{J.-L. Rols}

Université de Toulouse, UPS, INP; EcoLab

(Laboratoire d'écologie fonctionnelle et environnement),

118 route de Narbonne,

31062 Toulouse, France

J.-L. Rols

CNRS; EcoLab,

31062 Toulouse, France

$\begin{array}{ll}\text { CFU } & \text { Colony-forming units } \\ \text { DAPI } & \text { 4',6-Diamidino-2-phenylindole } \\ \text { DBS } & \text { Dodecyl benzene sulfonate } \\ \text { DHA } & \text { Dehydrogenase activity } \\ \text { DOC } & \text { Dissolved organic carbon } \\ \text { EU } & \text { European Union } \\ \text { INT } & \text { 2-(4-Iodophenyl)-3-(4-nitrophenyl)- } \\ & \text { 5-phenyltetrazolium chloride } \\ \text { INT-F } & \text { Formazan of 2-(4-iodophenyl)- } \\ & \text { 3-(4 nitrophenyl)-5-phenyltetrazolium } \\ \text { MLR } & \text { Mass loading rate } \\ \text { NTA } & \text { Nitrilotriacetic acid } \\ \text { OECD } & \text { Organization for the Economic Cooperation } \\ & \text { and Development } \\ \text { P/vP } & \text { Persistent/very persistent } \\ \text { PBT } & \text { Persistent, bioaccumulative, and toxic } \\ \text { PE } & \text { Pentaerythritol } \\ \text { PLFA } & \text { Phospholipid fatty acid } \\ \text { RBT } & \text { Ready biodegradability test } \\ \text { REACH } & \text { Registration, evaluation, and authorization of } \\ & \text { chemical substances } \\ \text { SA } & \text { Sodium acetate } \\ \text { SRT } & \text { Sludge retention time } \\ \text { TSS } & \text { Total suspended solids } \\ \text { vPvB } & \text { Very persistent and very bioaccumulative } \\ \text { VSS } & \text { Volatile suspended solids } \\ \text { WWTP } & \text { Wastewater treatment plant } \\ & \\ & \end{array}$

\section{Introduction}

Biodegradability can be defined as the intrinsic capacity of a substance to be structurally simplified by the action of microorganisms. It is one of the properties of the substances 
that determine their potential environmental hazard, and a desirable feature of chemicals used and then released to aquatic and terrestrial environments in large quantities. In the European Union (EU), the REACH (Registration, evaluation and authorization of chemical substances) system is new substance-oriented legislation based on the precautionary principle, whereby chemicals are considered to be unacceptably hazardous until proven otherwise [1]. According to $\mathrm{REACH}$, data on biodegradation properties are required for classification, labelling, and packaging of a substance, and for registration of any chemical produced or imported into the EU in quantities higher than 10 tons per year and per manufacturer or importer [2].

The OECD methodology offers a tiered approach for measuring biodegradability [3]. The first-tier tests (i.e., the 301 series of ready biodegradability tests, RBT) are simple screening assays providing limited time (typically 28 days) and opportunity for biodegradation to occur, because the test substance is provided as the sole source of carbon and energy and small amounts of unadapted inoculum are used [4]. The second tier consists of inherent biodegradability tests, which involve a prolonged exposure of the chemical to the microorganisms and make the conditions more favourable for biodegradation, as in the 302 series of OECD tests. The highest tier refers to simulation tests in well-defined environments (i.e., aerobic sewage treatment facilities in the OECD 303 series) to assess degradation kinetics, half-life times, and degradation products. Under current REACH legislation, positive results in an RBT or in an inherent test allow the assumption that the chemical will not persist in the environment [5]. The lack of biodegradation $(<20 \%)$ in an inherent test provides sufficient evidence to expect persistence, and hence the chemical is regarded as a preliminary "P/vP" (persistent/very persistent) substance in a $\mathrm{PBT} / \mathrm{vPvB}$ (persistent, bioaccumulative and toxic/very persistent and very bioaccumulative substance) assessment [5].

It is widely recognized that mixed cultures have a higher biodegradation potential than axenic ones, as a microbial community is able to use a wider variety of substrates because of the collective action of individual species [6, 7]. Consequently, biodegradability tests are inoculated with natural populations of microorganisms to ensure the presence of a multiplicity of species and to mimic, to some extent, actual ecosystems or man-made environments. Activated sludge is regarded as a suitable and diverse source of microorganisms, and thus is the most common inoculum for biodegradation tests. Assays inoculated with activated sludge give an impression of a microbial community present in a wastewater treatment plant (WWTP), and their results are environmentally relevant as a preliminary assessment of the fate of chemicals during sewage treatment.
Although a complex and undefined inoculum leads to more representative results in biodegradability studies, its use has several drawbacks. Ideally, activated sludges from different WWTPs would be similar enough to lead to comparable and reliable results, depending only on the molecular structure of the test compound. Nevertheless, geographical and temporal differences in the structure and function of activated sludge communities are broadly reported $[8,9]$. Because any microbial population can to adapt to any assimilable carbon source, variations in the inoculum affect mainly the reproducibility of tests on not readily biodegradable compounds. When the biodegradability of these substances is tested, the results depend both on their chemical structure and the composition of the inocula (i.e., the specific fraction of the viable biomass able to grow on the chemical).

This article overviews the factors affecting both the characteristics of activated sludge and the results of biodegradation tests. The methods used to reduce the variations associated with the inoculation of activated sludge are also presented and discussed. Special attention is devoted to the use of surrogates in biodegradability testing.

\section{Microbiology of the activated sludge process}

Activated sludge is a specialized, aerobically-grown culture containing flocculated and non-flocculated organisms. The heterotrophic bacteria aggregated in the flocs and freely dispersed in the liquor constitute the most abundant microbial group. Based on DAPI staining (4',6-diamidino2-phenylindole; imparting fluorescence to DNA), the number of bacteria has been estimated to be in the range from $1 \times 10^{12}$ to $10 \times 10^{12}$ per gram of VSS (VSS: volatile suspended solids) [10]. The percentage of metabolically active cells is typically around $80 \%$ of this total count [10]. Autotrophic nitrifying bacteria and fungi may be present, but algae are normally absent. Protozoa (classified into flagellates, sarcodines, and ciliates) are virtually ubiquitous in activated sludge, frequently reaching a large proportion (around 5\% of the dry weight of solids [10]). Some metazoa (classified into rotifers and nematodes) may also occur. In this man-made ecosystem, protozoa act as predators of bacteria and fungi, serving also as food source of metazoa. In addition to improving effluent quality, protozoan grazing of dispersed bacteria is regarded as a major factor shaping the bacterial community in activated sludge [10].

Conventional studies with culturable isolates have shown that microorganisms of the Proteobacteria phylum predominate in activated sludge. In fact, this bacterial group 
can be regarded as the main group responsible for pollutant removal [11]. In activated sludge from a municipal WWTP, the most common culturable isolates are Gram-negative, non-fermentative, and oxidase-positive bacteria [12]. The usual genera detected are Zoogloea, Pseudomonas, Achromobacter, Alcaligenes, Comamonas, and Flavobacterium. These culture-dependent techniques have also confirmed that bacterial diversity in activated sludge is different from that present in the sewage entering the plant, where Escherichia coli, Streptococcus faecalis, Salmonella typhi, and $P$. aeruginosa are commonly found [12].

Microbial community analysis based on fluorescent in situ hybridization (FISH) and clone library data using $16 \mathrm{~S}$ rRNA sequence comparisons indicate that culturedependent methods are selective and then they do not provide an actual activated sludge structure [13]. For instance, culture on nutrient-rich agar plates resulted in Acinetobacter ( $\gamma$ class of Proteobacteria) being responsible for $30-60 \%$ of total colony, forming units (CFU), whilst its abundance was estimated between 3-9\% when a cultureindependent technique was employed [14]. By using group and genus specific rRNA oligonucleotide probes, the relative abundance of Proteobacteria was confirmed, as its $\alpha, \beta$, and $\gamma$ classes accounted for approximately $80 \%$ of all active bacteria found in activated sludge samples [13]. However, the predominance of organisms belonging to the Betaproteobacteria class has also been established [13, 14]. The genera Hydrogenophaga, Comamonas and Acidovorax, which are well known for utilization of a wide range of carbon sources and seem therefore to be well-suited to wastewater treatment, are also included in this group and are now regarded as among the dominant bacteria in activated sludge [14].

Culture-independent methods have enabled the detection of large numbers of previously undescribed species of the Actinobacteria, Chloroflexi, Bacteroidetes, and Firmicutes phyla, along with the unusual Planctomycetes [10, 13-15]. Chloroflexi includes representatives of bulking filamentous bacteria. Nostocoidia limicola, another filamentous bacterium, belongs to the Actinobacteria phylum. Methanogenic Archaea (Euryarchaeota phylum) may also occur in activated sludge, where they account for $<1 \%$ of the total cells [10].

Bacteriophages are another important group in activated sludge, able to change the microbial diversity of the ecosystem by driving bacterial lysis [16, 17]. The presence of bacteriophages in activated sludge is a result of their abundance in sewage (as E. coli phages) and of their own multiplication in the system [17]. Some phages, for example those hosted by enteric bacteria, seem to decline in numbers, even by ten orders of magnitude, during the activated sludge process [18]. By contrast, 3.5 to 18.3 -fold augmentations of the amount of phage-like particles through the treatment have also been reported [16]. Temporal dynamics of both phages infecting specific bacterial strains and their hosts have been demonstrated by several studies $[19,20]$. This correlation between host abundance and phage counts is consistent with the "killing the winner" hypothesis, establishing that a rise in abundance of a bacterial strain leads to a rise in the counts of its specific phage [19]. Several methodological problems with phage quantification and detection are responsible for hindering the assessment of their actual abundance and diversity in activated sludge. Consequently, the role of bacteriophages in the performance of the activated sludge process remains unclear [10].

\section{Effect of selective pressures on activated sludge communities}

It is commonly assumed that activated sludge plants of similar configurations and treating wastewater of similar composition will have roughly similar microbial community structure, regardless of their location [10]. However, the microbial populations found in activated sludge are responding continuously to changes in environmental conditions. In addition to the influent wastewater composition, the presence of toxic compounds, excess or deficiency of specific nutrients, $\mathrm{pH}$, and the concentration of dissolved oxygen in the aeration tank can exert selective pressures on both the microbial structure and function of the sludge. A minor change in the environmental conditions may lead to restructuring of the community, even if the change affects only a limited number of microbial species [9]. So, activated sludge structure is now regarded as being in dynamic equilibrium rather than under "steady-state" conditions. This dynamic equilibrium arises also from the natural process of competition between microorganisms for essential resources, which is controlled mainly by the sludge retention time (SRT) or sludge age [21]. SRT is the mean residence time of cells in the plant, and its value may yield oscillations in the abundances of species. For instance, abundances of protozoa and metazoa are positively related to higher SRT [22, 23] and presumably to lower cell densities in the dispersed phase. It has been also reported that bacterial communities in younger sludges (i.e., cultivated at low SRT) have a higher diversity of genotypes than bacterial groups in older sludges [22]. As diversity is positively related to ecosystem stability, SRT is a key condition driving resistance to disturbances and resilience (rate of recovery after a disturbance) in activated sludge systems [21]. 
The mass loading rate (MLR), commonly referred to as the food-to-microorganism ratio, is the daily organic matter load per biomass quantity. The MLR is controlled by sludge wasting rates; if these are high, sludge age decreases and MLR increases. The MLR determines the rate of biological oxidation and the volume of new biomass by maintaining microbial growth in the log, declining, or endogenous growth phases [23]. In a high-MLR (and consequently with a low sludge age) process, the microbial community has a high proportion of organisms in the stationary and even log growth phases, as there is excess substrate available per unit of biomass. Under these conditions, the rate of metabolism is enhanced and the microbial activity is higher. In contrast, in a low-MLR system (i.e., in an extended aeration plant) the quantity of organic substrate is low in relation to sludge mass, and the microorganisms become nutrient-starved. In this case, a larger proportion of dead cells exists, and most of the living microorganisms are in an endogenous phase.

The characteristics of activated sludges collected in municipal WWTP operating at low, mean, and high MLR $\left(0.1,0.5\right.$, and $0.9 \mathrm{~kg} \mathrm{BOD}_{5} \mathrm{~kg} \mathrm{VSS}^{-1} \mathrm{~d}^{-1}$, corresponding to SRT of 30,5 , and 3 days, respectively) were compared in a previous study [24]. Total cell counts were quite homogeneous in these sludges (in the range $1.1 \times 10^{12}$ to $1.7 \times 10^{12}$ cells g TSS $^{-1}$ ) (TSS: total suspended solids). However, the cultivable cell contents were higher in the sludge from the process operated at the highest MLR. The higher level of activity of this sludge was confirmed by its specific oxygen uptake rate and by its dehydrogenase activity (DHA), which assesses the bulk potential of sludge to oxidize carbonaceous substrates. Three inocula were prepared by settling of the sludges and recovery of the supernatants, which were then analysed. The densest inoculum was the high-MLR supernatant, as indicated by its higher active and cultivable cell contents. This supports the idea that a low SRT favours the growth of dispersed bacteria (probably by limiting protozoan growth and grazing), as mentioned above. High-MLR supernatant also had higher respiratory activity and a wider range and magnitude of hydrolytic activity determined by the API-ZYM system. These characteristics suggest that the high-MLR sludge has a biodegradation potential higher than that originating from the low-MLR treatment plant, which may be also attributed to the cell starvation induced by these last processes [23].

\section{Effect of cell density on biodegradability tests}

For some OECD methods of the first tier (301 A, B and F), the inoculation level is specified only in terms of volume of sample per volume of test medium, with a maximum density threshold (30 $\mathrm{mg}^{\mathrm{TSS}} \mathrm{L}^{-1}$ ) of unadapted biomass established as sole control [4]. As a consequence, biodegradation of a given chemical is less likely to occur in those RBT than in an inherent test, for example the Zahn-Wellens assay, which is inoculated with $0.2-1 \mathrm{~g} \mathrm{TSS} \mathrm{L}^{-1}$ of activated sludge [25]. With a decrease in the cell density, the number of organisms able to degrade a specific chemical in the test vessel also decreases [26]. It may be also expected that the fraction of biomass able to grow on a xenobiotic chemical is lower than the fraction growing on substances commonly found in sewage. Previous ring studies have shown that the percentage of positive results in biodegradability tests is approximately proportional to the logarithm of the total viable cell density at the beginning of the test [27]. In this way, Zahn-Wellens test gave $79-98 \%$ positive results, whereas in RBT this value varied around $40 \%$.

The most stringent RBT of the 301 OECD series are the tests $301 \mathrm{D}$ and $\mathrm{E}$, because of their low cell density. In these methods, a more dilute inoculum without sludge flocs is needed and hence raw sewage or a secondary effluent from a domestic WWTP are preferred (one drop $\mathrm{L}^{-1}$ and $0.5 \mathrm{~mL} \mathrm{~L}^{-1}$, respectively). After biodegradation of 29 chemicals in several OECD tests, it was found that the 301 $\mathrm{D}$ and $\mathrm{E}$ assays gave 14 and $38 \%$ of positive results whereas the 301 B test provided 54\% [6]. During a study of the biodegradability of 16 chemicals [28], the $301 \mathrm{D}$ test was found to be as stringent as the 20-day BOD test (BOD: biochemical oxygen demand), irrespective of the inoculum used (i.e., filtered sewage, secondary effluent, or Polyseed, a commercial BOD seed). It was concluded that both tests can be interchangeably used, which also suggests that these sources have equivalent biodegradation potential toward readily biodegradable substances.

\section{Effect of different activated sludge sources in biodegradability tests}

The MLR (via the SRT) of a treatment plant exerts a selective pressure on activated sludge, and modifies its diversity, physiological state, and biodegradation potential. So, the choice of a given activated sludge source affects both the rate of biodegradation and the biodegradability test results. This could explain the results of other authors [29], who tested the biodegradation of dodecyl benzene sulfonate (DBS, a borderline case of ready biodegradability) in closed-bottle assays and obtained positive results using a sludge from a municipal WWTP with an SRT of 6 days (mean MLR), while the sludge derived from a WWTP with an SRT of 30 days (low MLR) yielded negative results.

Ready biodegradability of DBS was assessed in other work [24] by using supernatants withdrawn from activated 
sludges of municipal WWTP operating at high, mean, and low MLR. Inoculation on a volume basis with the highMLR supernatant led to a faster biodegradation pattern and to the shortest lag phase (time necessary to achieve $10 \%$ biodegradation; Table 1). These inocula were also used for testing the biodegradability of nitrilotriacetic acid (NTA) and pentaerythritol (PE) [30], chemicals with erratic behaviour in ring biodegradability studies. As for DBS, the fastest kinetics were obtained with the high-MLR supernatant, and the same trend was observed when more biodegradable compounds, for example aniline and sodium acetate (SA), were evaluated in standard RBT. In this way, the test outcome is affected by the choice of a sludge source, because an active, high density inoculum is more likely to be obtained when activated sludge is sampled from a high-MLR treatment plant. Although a positive RBT result seems more probable with such an inoculum, more studies with non-readily biodegradable chemicals are needed to confirm this.

\section{Use of preconditioned inocula}

The OECD guidelines suggest preconditioning the inocula obtained from activated sludge or from secondary effluents by means of aeration for 5-7 days at the test temperature [3]. Preconditioning is intended to overcome the stress of transfer into the test medium and to reduce the endogenous respiration rates of sludges produced in high-MLR plants, because during this treatment the partially-degraded substrates present in the sludges can be oxidized. This aeration period is described as an optional alternative during the inoculum preparation, and so it is implicitly considered not to affect the spectrum or intensity of metabolic activity. In an earlier study [6], the biodegradation of PE was followed in flasks inoculated with fresh activated sludge and with the same sludge one week after shaking at the test temperature. By preconditioning, the lag period was reduced from $14.3 \pm$ 2.8 to $11.9 \pm 3.3$ days, but there was no significant difference in dissolved organic carbon (DOC) removal neither was there variability in the assay between the two types of inocula $(94 \pm 1 \%$ and $97 \pm 2 \%$ for the preconditioned and the fresh sludges, respectively).

In previous research [31], the possibility of homogenizing the characteristics of various activated sludges by means of preconditioning was explored. As mentioned earlier, the sludges cultivated in WWTP operating at different MLR (high, mean, and low MLR) were markedly heterogeneous in terms of cultivable cell density and dehydrogenase activity (measured as the reduction of 2(4-iodophenyl)-3-(4 nitrophenyl)-5-phenyltetrazolium chloride, INT, to the corresponding formazan salt, INT-F). After a 7-day aeration period in a mineral medium and under agitation, these properties diminished significantly (Fig. 1). However, the measured characteristics of the supernatants were homogenized, because their cultivable cell contents (varying initially between $1.1 \times 10^{8}$ and $1.7 \times$ $10^{9} \mathrm{CFU} \mathrm{L}^{-1}$ ) were similar after preconditioning, with values between 1 and $2.4 \times 10^{7} \mathrm{CFU} \mathrm{L}^{-1}$.

The raw and preconditioned supernatants were used afterwards for testing the ready biodegradability of SA and aniline. The tests inoculated with non-preconditioned supernatants had variable lag times $(6.7-13.6 \mathrm{~h}$ and $36.9-60.1 \mathrm{~h}$ for SA and aniline tests, respectively), depending on the source of the sludge. In both cases, the high-MLR supernatant led to the shortest lag phase. When preconditioned supernatants were
Table 1 Results of biodegradability tests using supernatants of sludges from different WWTP as inocula

\footnotetext{
a Inoculation with sludge supernatant at $10 \% v / v$, OECD 301 A test [13]

${ }^{\mathrm{b}}$ Inoculation with sludge supernatant at $1 \% v / v$, OECD 301 B test [15]

${ }^{\mathrm{c}}$ Inoculation with sludge supernatant at $1 \% v / v$, OECD 301 A test [15]

${ }^{\mathrm{d}}$ Inoculation with sludge supernatant at $1 \% v / v$, OECD 301 A test [17]
}

\begin{tabular}{|c|c|c|c|}
\hline $\operatorname{MLR}\left(\mathrm{kg} \mathrm{BOD}_{5} \mathrm{~kg} \mathrm{VSS}^{-1} \mathrm{day}^{-1}\right)$ & $\operatorname{High}(0.9)$ & Mean $(0.5)$ & Low $(0.1)$ \\
\hline \multicolumn{4}{|c|}{ Sodium dodecylbenzene sulfonate (DBS) assays $\mathrm{s}^{\mathrm{a}}$} \\
\hline$X_{0}\left(\mathrm{CFU} \mathrm{L}^{-1}\right)$ & $6.9 \times 10^{8}$ & $2.1 \times 10^{8}$ & $7 \times 10^{5}$ \\
\hline Lag time (days) & 2.8 & 5.5 & 8.7 \\
\hline \multicolumn{4}{|l|}{ Nitrilotriacetic acid (NTA) assays ${ }^{\mathrm{b}}$} \\
\hline$X_{0}\left(\mathrm{CFU} \mathrm{L}^{-1}\right)$ & $5.1 \times 10^{7}$ & - & $4.4 \times 10^{6}$ \\
\hline Lag time (days) & 8.0 & - & 11.0 \\
\hline \multicolumn{4}{|l|}{ Pentaerythritol (PE) assays ${ }^{\mathrm{c}}$} \\
\hline$X_{0}\left(\mathrm{CFU} \mathrm{L}^{-1}\right)$ & $3.1 \times 10^{6}$ & - & $1.1 \times 10^{7}$ \\
\hline Lag time (days) & 7.1 & - & 9.6 \\
\hline \multicolumn{4}{|l|}{ Sodium acetate (SA) assays ${ }^{\mathrm{d}}$} \\
\hline$X_{0}\left(\mathrm{CFU} \mathrm{L} \mathrm{L}^{-1}\right)$ & $1.7 \times 10^{7}$ & $1.1 \times 10^{6}$ & $2.6 \times 10^{6}$ \\
\hline Lag time (h) & 6.7 & 13.6 & 11.7 \\
\hline \multicolumn{4}{|l|}{ Aniline assays $^{\mathrm{d}}$} \\
\hline$X_{0}\left(\mathrm{CFU} \mathrm{L}^{-1}\right)$ & $1 \times 10^{8}$ & $1.7 \times 10^{6}$ & $1 \times 10^{6}$ \\
\hline Lag time $(\mathrm{h})$ & 36.9 & 47.9 & 60.1 \\
\hline
\end{tabular}



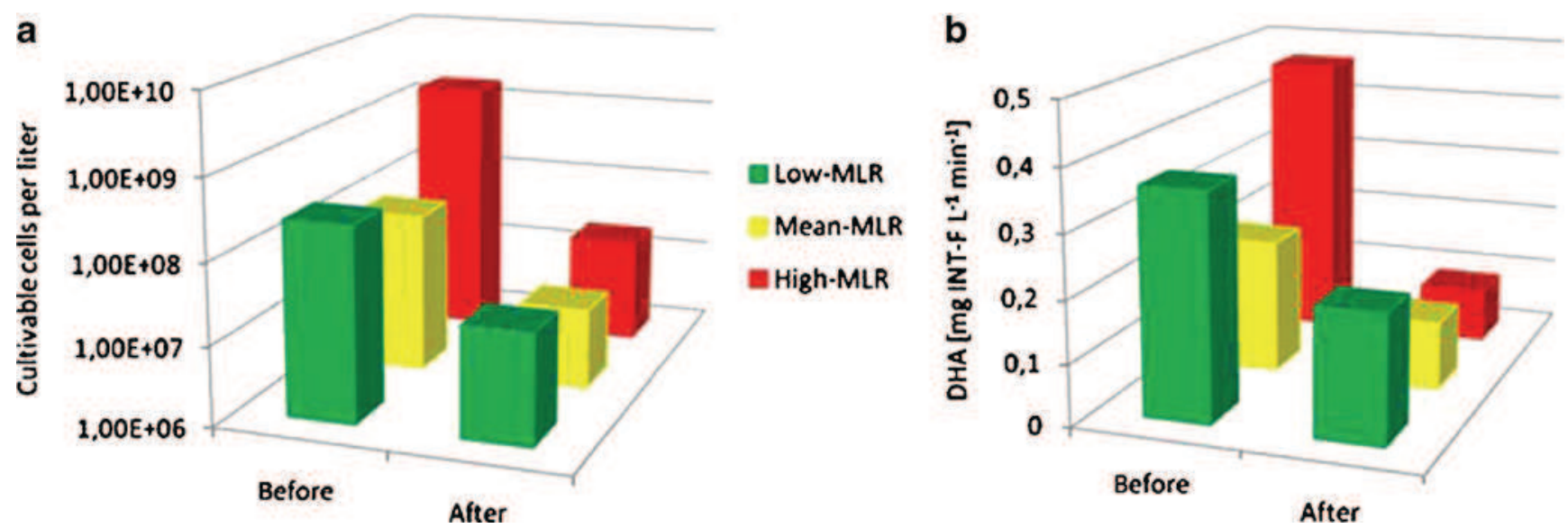

Fig. 1 (a) Cultivable cell densities and (b) dehydrogenase activity of three inocula obtained from different WWTP before and after preconditioning

used, SA biodegradation kinetics were relatively homogeneous and the lag times varied between 11.3 and $12.6 \mathrm{~h}$. These lag times were higher than those obtained with nonpreconditioned inocula, contrary to the results reported for PE by Painter [6]. In the aniline tests, however, use of preconditioned inocula did not enable homogenization of the biodegradation kinetics, because only the mean-MLR supernatant could mineralize this chemical during a $90 \mathrm{~h}$ observation period.

As evidenced by these results, a deprivation period leads to a decrease in the activity and viability of the microorganisms, and in the biodegradation potential. In axenic cultures of Ralstonia eutropha, phenol-oxygenating activity was completely lost after a 7-day starvation period [32]. The starvation of microbial populations could cause the death and lysis of some species, whereas opportunistic ones could grow on the cellular material released depending on their ability to adapt to this substrate depletion. Because xenobiotic degradation is accomplished mainly by specialized bacterial groups, the ability to degrade a synthetic chemical such as aniline can be diminished or even lost because of the starvation-induced disappearance of a microbial species. On the other hand, the biodegradation of easily assimilable chemicals such as SA is carried out by more abundant, generalist bacterial populations and so its oxidation is more likely to occur, even after a starvation period. False-negative results can be expected in RBT inoculated with sludges subjected to a deprivation period, and consequently preconditioning is not well suited to homogenizing the quality of the inocula in these assays.

\section{Use of precultured inocula}

Preculture of the inoculum in a medium not provided with the test chemical has been suggested for improving the reproducibility of biodegradability assays. In the OECD testing scheme [3], this treatment is considered only in the MITI tests (301 C and $302 \mathrm{C}$ of ready and inherent biodegradability evaluation, respectively). Initially, MITI inoculum is made up of at least ten natural sources, i.e. activated sludges, soils, surface or sea waters. The mixture of these samples is settled and the supernatant is grown on a glucose and peptone-based medium in semi-continuous mode. After one month of operation, the sludge may be used as an inoculum.

Although multiple sources are likely to increase the microbial diversity, this may be weakened or lost during the long preculture process of the MITI tests. Analysis of biomass levels, substrate utilization patterns and phospholipid fatty acid (PLFA) profiles revealed differences among freshly collected activated sludge samples and the same sludges after a standard MITI preculture [9]. In addition, precultured inocula contained greater numbers of Grampositive bacteria, with large depletion of heterotrophic eukaryotes. As significant differences in the substrate utilization patterns and in the PLFA profiles were detected during the preculture, a continuous shift in the dominant species is likely to occur. Changes in the inoculum structure induced by the long MITI preculture have been used to explain some loss of biodegradation potential of the sludges $[33,34]$.

In other work [35], eight samples of activated sludge and eight samples of river water were precultured in a chemostat-type reactor with sodium acetate as the only source of carbon. The preculture enabled reduction of the variability of the inocula in terms of total cell count and endogenous dehydrogenase activity. However, when the biodegradation of PE and $p$-nitrophenol was tested, precultured inocula did not lead to an improved reproducibility of the assays. Resource competition theory predicts that competitive exclusion among species would occur during 
continuous cultivation under constant environmental conditions, resulting in reduction of the microbial diversity and physiological potential of the sludge [9].

Short-term batch preculture on a complex substrate (yeast extract) was tested in an attempt to homogenize the characteristics of activated sludges from WWTP operating at different MLR (high, mean, and low). In Fig. 2a the counts of total, active and cultivable cells measured in the inocula are shown. Inocula were the sludge supernatants obtained after settling for $30 \mathrm{~min}$. The total cells were measured by DAPI staining, the active cells were counted by the INT method, and the cultivable cell density by plating in solid non-selective medium; these methods are fully described elsewhere [24]. The inocula had similar total $\left(1.46-4.2 \times 10^{12}\right)$ and active $\left(1.02-1.8 \times 10^{12}\right)$ cell densities; the main difference being the cultivable cell count of the high-MLR supernatant $\left(1.49 \times 10^{9}\right)$, which was one order of magnitude higher than those found in the other supernatants $\left(1.2-1.84 \times 10^{8}\right)$. After $14 \mathrm{~h}$ of preculture, the total $\left(8.68 \times 10^{13}-1.42 \times 10^{14}\right)$, active $\left(3.16-4.42 \times 10^{12}\right)$, and cultivable $\left(5.0-7.6 \times 10^{10}\right)$ cell contents of the inocula were augmented to similar levels (Fig. 2b). These inocula were used to test the biodegradability of two easily assimilable chemicals (SA and aniline) and two xenobiotic compounds (NTA and PE) showing erratic behaviour in biodegradation studies [6]. The biodegradability test used was the OECD 301 A test, based on the consumption of DOC. Inoculation was at $1 \%(v / v)$. The results, in terms of half-life times, are shown in Table 2.

In all the tests inoculated with non-precultured sludges the chemicals could be biodegraded. As mentioned above, the kinetics of biodegradation depend strongly on the inoculum source. High-MLR inoculum had the lowest half-life times, probably because of its higher cell density. Preculture of supernatants enabled the inoculation of tests with very similar levels of total, active, and cultivable cells.
In the case of easily assimilable compounds (aniline and SA), this also enabled their kinetics of biodegradation to be homogenized. However, for the less biodegradable compounds NTA and PE, inocula had a lower biodegradation potential after preculture. Apparently, even a short preculture imposes distinct selective pressures on activated sludges and causes a new community structure to appear, maybe not fairly simulating the original structure.

Recently, a study has pointed out that reactor operation (semi-continuous vs. continuous), nature of the carbon source (simple vs. complex), loading rate, reactor configuration, and addition of exogenous bacteria can modify the microbial diversity in bioreactors [36]. However, microbial diversity could not to be systematically increased in that study. To avoid the selection of specific populations with high affinity for the substrates used, and to maintain high microbial diversity, continuous changing of the frequency, composition, and amount of substrate feed has been suggested [9]; this undoubtedly increases the complexity of the preculture method.

Batch or continuous, on complex or defined media, preculture has a strong effect on the microbial quality and quantity of activated sludge. This leads to a diminution in the biodegradation potential of inocula, especially for xenobiotic compounds, and could give more false negative results in RBT. Because preculture does not seem to increase the reproducibility of biodegradation tests, it should be avoided even in its standardized form (i.e. MITI test procedure) for screening purposes.

\section{Use of inocula preadapted to the test chemical}

Preadaptation has been defined as the preincubation of an inoculum in the presence of the test substance with the purpose of enhancing the ability of the inoculum to degrade


Fig. 2 Total, active, and cultivable cell densities of three inocula obtained from different WWTP (a) before and (b) after preculture on complex substrate 
Table 2 Half-life times (h) obtained in OECD 301 A tests inoculated with non-precultured and precultured sludges from different WWTP

\begin{tabular}{|c|c|c|c|c|c|c|c|c|}
\hline \multirow[b]{2}{*}{ Inoculum } & \multicolumn{4}{|c|}{ Tests with non-precultured inocula } & \multicolumn{4}{|c|}{ Tests with precultured inocula } \\
\hline & SA & Aniline & NTA & $\mathrm{PE}$ & SA & Aniline & NTA & PE \\
\hline High-MLR & 8.5 & 43.5 & 115 & 190 & 5.2 & 35.3 & NB & NB \\
\hline Mean-MLR & - & 50.8 & - & - & - & 35.3 & - & - \\
\hline Low-MLR & 12.5 & 59.6 & 165 & 248 & 5.2 & 36.3 & NB & NB \\
\hline
\end{tabular}

SA, sodium acetate; NTA, nitrilotriacetic acid; PE, pentaerythritol

$\mathrm{NB}$, not biodegraded in the observation period $(288 \mathrm{~h})$

it [6]. For a readily biodegradable compound, for example $p$-nitrophenol, it has been found that a total concentration of $5 \times 10^{10}$ cells $\mathrm{L}^{-1}$ is needed to ensure $99.9 \%$ success in a 28 day biodegradability test [26]. However, such a high cell concentration in an indigenous inoculum leads to important organic contamination in the assay. As preadaptation of the inoculum to the test compound enables the number of specific biodegraders to be increased without introducing excess exogenous carbon, it has been suggested for augmenting the reproducibility of RBT. In fact, a similar test response can be obtained when an adapted inoculum contains at least $1.2 \times 10^{5}$ specific biodegraders per litre [26]. Use of preadapted inocula also enables diminution of lag times; for $p$-nitrophenol, lag periods were between 2.8 and $52 \mathrm{~h}$ when adapted populations were used, whereas lag times for non-adapted inocula can reach several weeks [26].

Preadaptation is affected by the pre-exposure period to the test chemical, among other factors. The ability of sludges to degrade 11 chemicals was studied by varying the length of exposure in semi-continuous units over a 67-day period [6]. The sludges were taken at various times $(10,18$, 26 , and 67 days), and then used to inoculate an ISO test based on DOC consumption. Two chemicals, $N$-methylaniline and $t$-butanol, were only biodegraded when preadapted inocula were used. For some chemicals (PE, 3-chlorobenzoic acid, and 2-nitrobenzoic acid), the time required to achieve the test pass level (DOC removal $>70 \%$ ) diminished as the exposure period of the inoculum was augmented. For sulfanilic acid and diethylene glycol, adaptation of the inocula led to erratic results, and benzene 1,3-sulfonic acid, and 2-chlorobenzoic acid were not degraded by any of the adapted sludges or by the original inoculum.

Although adaptation is a process of crucial importance in the real environment (e.g., in natural media exposed intermittently to a chemical), regulatory authorities have traditionally ruled out preadaptation in RBT to avoid falsepositive results. If a chemical compound does not reach the pass level in an RBT, the OECD recommends performing an inherent biodegradability test [3]. REACH has recently introduced several enhancements of the RBT to assist in the prioritization of $\mathrm{PBT} / \mathrm{vPvB}$ assessments by reducing the need for higher-tier testing [5]. These enhancements include an increase in the duration of the test to 60 days (if biodegradation is still occurring on day 28) and the possibility of adapting the biomass to the test compound. So, semi-continuous biodegradability tests and low-level preadaptation (consisting in the use of a sample from a completed RBT to seed a subsequent RBT) are now allowed. In this way, for PBT/vPvB assessment, a substance reaching the pass level in an enhanced biodegradability test can be regarded as "not P" [5]. Enhanced RBT methods have still to be standardized and validated [37].

\section{Use of surrogate microbial communities}

Several workers have pointed out the need for a certified biological material with the same metabolic potential as an activated sludge that can be used for quality control and to provide traceability [38-41]. So, the use of surrogate cultures has been proposed to fulfil the need of an activated sludge with constant characteristics. The reliability of two commercial inocula (Bi-Chem and Biolen) has been studied in standard $\mathrm{BOD}_{5}$ tests [38]. For both inocula, the assay reproducibility was adequate when a standard solution of glucose and glutamic acid was tested because the variation around the mean $\mathrm{BOD}_{5}$ value was between 4.52 and $9.37 \%$. These commercial inocula and activated sludge were used to test the $\mathrm{BOD}_{5}$ of several wastewater samples, and the results were found to be significantly correlated (95\% confidence). This correlation was explained by the similarity of microbial strains found in the three inocula by means of the API identification system: Gram-positive, aerobic, spore-forming bacteria of the genus Bacillus and Gramnegative bacteria belonging to the genera Enterobacter and Pseudomonas. In another study [39], the substrate utilization patterns of Bi-Chem and Biolen were studied and compared with that of activated sludge by using Biolog plates. Activated sludge was positive for all the 31 carbon sources tested, whereas Bi-Chem and Biolen were considered positive for 30 and 22 substrates, respectively. From the authors' point of view, the overall similarity of catabolic 
profiles observed between activated sludge and Bi-Chem supports its use as surrogate inoculum.

Use of commercial inocula (i.e., BOD seed, Bi-Chem and Polyseed) was also studied for testing biodegradable dissolved organic carbon (BDOC) [42]. The performance of the commercial inocula was compared with that of activated sludge and indigenous inocula for a standard solution of sodium tartrate, surface waters, and secondary effluents. Commercial seeds had similar BDOC exertion levels with analogous kinetics in all tests, but they tended to underestimate the actual BDOC values of the samples. The activated sludge inoculum provided higher and more accurate BDOC values, and faster exertion kinetics than the commercial and indigenous inocula. This fact was explained by the wider species diversity and the greater number of acclimated cells of the activated sludge samples. Because activated sludge also resulted in the lowest coefficients of variation, it can be regarded as the most suitable inoculum for the BDOC test.

The potential of Bi-Chem and Biolen to be used as alternative inocula to activated sludge was evaluated by assessing the biodegradability of diethylene glycol in the Zahn-Wellens assay [40]. Whereas complete biodegradation was achieved in 10-12 days with activated sludge, none of the commercial seeds reached the test validity criterion (biodegradation $>70 \%$ on the 14th day, [25]). Tabka et al. [43] also studied the biodegradability of several chemicals in the Zahn-Wellens assay using activated sludge and Actizym, a commercial seed. Both inocula degraded ethylene glycol with almost identical kinetic patterns; however, activated sludge had a higher biodegradation potential, because 1,4-nitrophenol was degraded only when this inoculum was used. To the best of our knowledge, no commercial surrogate has been tested in the RBT, and so their usefulness for improving the reproducibility of these assays has not been demonstrated.

Another approach consists in using a representative model composed of a reduced number of bacterial species. Well-defined mixtures containing 4 to 8 selected bacterial strains in equal proportions were compared with an activated sludge in terms of substrate utilization patterns measured by Biolog plates [41]. The strains studied were Acinetobacter sp., Enterobacter sp., Xanthomonas sp., Staphylococcus capitis, Pseudomonas sp., P. putida, Bacillus subtilis, and B. cereus, which are nonpathogenic species commonly found in water and soil. Because four of these mixtures (composed of four to six strains) had repeatable functional diversity similar to that of an activated sludge, they were suggested as potential biological reference material in activated sludge-based bioassays. In a study already mentioned [40], a defined consortium composed of equal parts of six bacterial strains (i.e., Acinetobacter sp., Enterobacter sp., S. capitis, P. putida, B. subtilis and B. cereus) was compared with activated sludge samples using diethylene glycol as reference chemical in the ZahnWellens assay. Among the surrogates, the defined consortium behaviour was the most similar to that of activated sludge, although not as fast.

Although surrogates have some similarities to activated sludge (i.e., catabolic profile) and equivalent behaviour with regard to easily assimilable compounds, they do not seem to provide more reproducible results with regard to the ability to degrade either xenobiotic chemicals or persistent samples (as organic carbon in secondary effluents). The performance of the surrogates has been only studied in the Zahn-Wellens test, which uses a high concentration of biomass. Therefore, it is unlikely that they enable RBT reliability to be increased.

\section{Concluding remarks}

Activated sludges are, with secondary effluents, the most utilized sources of inocula for biodegradation tests. This is mainly because of their availability, and specific general features (for example their continuous exposure to sewage and their aerobic character) that make them more consistent than other natural sources. These general features are not sufficient to ensure a limited variability range of inoculum quantity and quality for testing ready biodegradability with standard methods. Differences in the structure and activity of activated sludge communities could arise from dissimilarities in wastewater composition, but largely from WWTP operation (i.e., MLR or SRT).

However, activated sludges are a relevant inoculum because their use in biodegradation studies enables a preliminary approach to the fate of chemicals during wastewater treatment. Furthermore, activated sludges seem to have substantial biodegradation potential, higher than that of other natural sources. The metabolic potential of activated sludge toward xenobiotic compounds can hardly be found in commercial surrogates or in other well-defined microbial consortia. It is our view that any manipulation of the inocula incurring in a diminution of their biodegradation potential, for example preconditioning or preculture, does not constitute an option for standardization.

Biodegradation experiments inoculated with fresh activated sludge simulate in a more realistic way the complexity of microbial processes occurring in aquatic environments. Such complex microbial assemblages are necessary for first-tier testing of chemicals, requiring maximum microbial diversity, even at the expense of reproducibility. For not readily biodegradable chemicals, for which there is a small number of specific degraders in environmental samples, this problem could be overcome by using inocula from different origins. Additionally, recent enhancements promoted by $\mathrm{REACH}$ 
(allowing low-level adaptation of inocula in RBT) have led to promising improvement of the reliability of ready biodegradation tests. Both alternatives have still to be standardized and validated for a wide set of chemicals.

Acknowledgements The authors sincerely appreciate the help of Mr Randall Lewis in improving the English of the manuscript.

\section{References}

1. Combes R, Barratt M, Balls M (2003) An overall strategy for the testing of chemicals for human hazard and risk assessment under the EU REACH system. ATLA 31:7-19

2. Foth H, Hayes AW (2008) Concept of REACH and impact on evaluation of chemicals. Hum Exp Toxicol 27:5-21

3. OECD (2006) Revised introduction to the OECD guidelines for testing of chemicals, Section 3. Organization for the Economic Cooperation and Development, Paris

4. OECD (1992) Ready biodegradability. OECD guideline for testing of chemicals. Organization for the Economic Cooperation and Development, Paris

5. European Chemicals Agency (2008) Guidance Information Requirements and Chemical Safety Assessment. Chapter R.11: PBT Assessment. http:/guidance.echa.europa.eu/docs/guidance document/information_requirements_r11_en.pdf?vers=20_08_08. Accessed April $3020 \overline{1}$

6. Painter HA (1995) Detailed review paper on biodegradability testing. Organization for the Economic Cooperation and Development, Paris

7. van Heerden J, Ehlers MM, Cloete TE (2001) Biolog for the determination of microbial diversity in activated sludge systems. Water Sci Technol 43(1):83-90

8. Hantula J, Kurki A, Vuoriranta P, Bamford DH (1991) Rapid classification of bacterial strains by SDS-polyacrylamide gel electrophoresis: population dynamics of the dominant dispersed phase bacteria of activated sludge. Appl Microbiol Biotechnol 34:551-555

9. Forney LJ, Liu WT, Guckert JB, Kumagai YK, Namkung E, Nishihara T, Larson RJ (2001) Structure of microbial communities in activated sludge: potential implications for assessing the biodegradability of chemicals. Ecotoxicol Environ Safety 49:40-53

10. Seviour RJ, Nielsen PH (2010) In: Seviour RJ, Nielsen PH (eds) Microbial ecology of activated sludge. IWA Publishing, London

11. Vainio EJ, Moilanen A, Koivula TT, Bamford DH, Hantula J (1997) Comparison of partial 16S rRNA gene sequences obtained from activated sludge bacteria. Appl Microbiol Biotechnol 48:73-79

12. Pike EB, Curds CR (1971) In: Sykes G, Skinner FA (eds) Microbial aspects of pollution. London, Academic Press

13. Wagner M, Amann R, Lemmer H, Schleifer KH (1993) Probing activated sludge with oligonucleotides specific for proteobacteria: inadequacy of culture-dependent methods for describing microbial community structure. Appl Microbiol Biotechnol 59:1520-1525

14. Snaidr J, Amann R, Huber I, Ludwig W, Schleifer KH (1997) Phylogenetic analysis and in situ identification of bacteria in activated sludge. Appl Microbiol Biotechnol 63:2884-2896

15. Wagner M, Loy A, Nogueira R, Purkhold U, Lee N, Daims H (2002) Microbial community composition and function in wastewater treatment plants. Anton Leeuw 81:665-680

16. Ewert DL, Paynter MJB (1980) Enumeration of bacteriophages and host bacteria in sewage and activated-sludge treatment process. Appl Environ Microbiol 39:576-583
17. Khan MA, Satoh H, Katayama H, Kurisu F, Mino T (2002) Bacteriophages isolated from activated sludge processes and their polyvalency. Water Res 36:3364-3370

18. Dias F, Bhat J (1965) Microbial ecology of activated sludge - II. Bacteriophages, Bdellovibrio, coliforms, and other organisms. Appl Microbiol 13:257-261

19. Shapiro OH, Kushmaro A, Brenner A (2010) Bacteriophage predation regulates microbial abundance and diversity in a fullscale bioreactor treating industrial wastewater. ISME J 4:327-336

20. Otawa K, Lee SH, Yamazoe A, Onuki M, Satoh H, Mino T (2006) Abundance, diversity, and dynamics of viruses on microorganisms in activated sludge processes. Microbial Ecol 53:143-152

21. Saikaly PE, Oerther DB (2004) Bacterial competition in activated sludge: theoretical analysis of varying solids retention times on diversity. Microbial Ecol 48:274-284

22. Chipasa K, Medrzycka K (2008) The influence of soluble microbial products on microbial community composition: hypothesis of microbial community succession. Polish J Microbiol 57(1):59-70

23. Gray NF (1990) Activated sludge - theory and practice. Oxford University Press, Oxford

24. Vázquez-Rodríguez G, Goma G, Rols JL (2003) Activated sludge as inoculum for ready biodegradability testing of chemicals: effect of source. Environ Technol 24:979-987

25. OECD (1992) 302 B Zahn-Wellens/EMPA test. Organization for the Economic Cooperation and Development, Paris

26. Thouand G, Capdeville B, Block JC (1996) Preadapted inocula for limiting the risk of errors in biodegradability tests. Ecotoxicol Environ Safety 33:261-267

27. Blok J (2000) Probability of biodegradation, a novel concept for improving chemical classification and risk assessment. Ecotoxicol Environ Safety 47:221-230

28. Waggy GT, Conway RA, Hansen JL, Blessing RL (1994) Comparison of 20-d BOD and OECD closed-bottle biodegradation tests. Environ Toxicol Chem 13:1277-1280

29. van Ginkel CG, Haan A, Luijten MLGC, Stroo CA (1995) Influence of the size and source of the inoculum on biodegradation curves in closed-bottle tests. Ecotoxicol Environ Safety $31: 218-223$

30. Vázquez-Rodríguez G (2000) Étude des possibilités de standardisation des inocula des tests de biodégradabilité facile: cas des boues activées de station d'épuration (in French). Ph.D. Thesis, Institut National des Sciences Appliquées de Toulouse, France

31. Vázquez-Rodríguez G, Garabétian F, Rols JL (2007) Inocula from activated sludge for ready biodegradability testing: homogenization by preconditioning. Chemosphere $68: 1447-1454$

32. Watanabe K, Miyashita M, Harayama S (2000) Starvation improves survival of bacteria introduced into activated sludge. Appl Environ Microbiol 66:3905-3910

33. Nyholm N (1991) The European system of standardized legal tests for assessing the biodegradability of chemicals. Environ Toxicol Chem 10:1237-1246

34. Gerike P, Fisher WK (1979) A correlation study of biodegradability determinations with various chemicals in various tests. Ecotoxicol Environ Safety 3:159-173

35. Thouand G, Block JC (1993) The use of precultured inocula for biodegradability tests. Environ Technol 14:601-614

36. Pholchan MK, Baptista JC, Davenport R, Curtis TP (2010) Systematic study of the effect of operating variables on reactor performance and microbial diversity in laboratory-scale activated sludge reactors. Water Res 44:1341-1352

37. European Chemicals Agency (2009) Guidance to Regulation (EC) No 1272/2008 on classification, labelling and packaging (CLP) of substances and mixtures. http://guidance.echa.europa.eu/docs/ guidance_document/clp_en.pdf. Accessed April 302011 
38. Paixão SM, Baeta-Hall L, Anselmo AM (2000) Evaluation of two commercial microbial inocula as seed in a 5-day biochemical oxygen demand test. Water Environ Res 72:282-284

39. Paixão SM, Santos P, Baeta-Hall L, Tenreiro R, Anselmo AM (2003) Alternative inocula as activated sludge surrogate culture for a toxicity test. Environ Toxicol 18:37-44

40. Paixão SM, Sàágua MC, Tenreiro R, Anselmo AM (2006) Biodegradability testing using standardized microbial communities as inoculum. Environ Toxicol 21:131-140
41. Paixão SM, Sàágua MC, Tenreiro R, Anselmo AM (2007) Assessing microbial communities for a metabolic profile similar to activated sludge. Water Environ Res 79:536-546

42. Khan E, Sy-Savane O, Jittawattanarat R (2005) Application of commercial biochemical oxygen demand inocula for biodegradable dissolved organic carbon determination. Water Res 39:4824-4834

43. Tabka H, Seignez C, Adler N, Pulgarin C, Péringer P (1993) Inoculum standardization for biodegradability tests. Biotechnol Lett 7:217-222 